\title{
Bile duct reconstruction following laparoscopic cholecystectomy in England
}

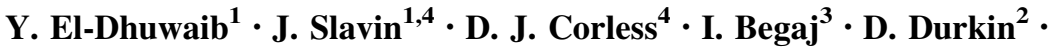 \\ M. Deakin ${ }^{1,2}$
}

Received: 16 July 2015/ Accepted: 22 October 2015/Published online: 29 January 2016

(c) The Author(s) 2016. This article is published with open access at Springerlink.com

\begin{abstract}
Objectives To determine the incidence of bile duct reconstruction (BDR) following laparoscopic cholecystectomy (LC) and to identify associated risk factors.

Background Major bile duct injury (BDI) requiring reconstruction is a serious complication of cholecystectomy.

Methods All LC and attempted LC operations in England between April 2001 and March 2013 were identified. Patients with malignancy, a stone in bile duct or those who underwent bile duct exploration were excluded. This cohort of patients was followed for 1 year to identify those who underwent BDR as a surrogate marker for major BDI. Logistic regression was used to identify factors associated with the need for reconstruction.

Results In total, 572,223 LC and attempted LC were performed in England between April 2001 and March 2013. Five hundred $(0.09 \%)$ of these patients underwent BDR. The risk of BDR is lower in patient that do not have acute cholecystitis [odds ratio (OR) 0.48 (95\% CI $0.30-0.76)]$. The regular use of on-table cholangiography (OTC) [OR 0.69 (0.54-0.88)] and high consultant caseload $>80$ LC/year [OR $0.56(0.39-0.54)$ ] reduced the risk of
\end{abstract}

\section{Deakin}

Mark.Deakin@uhns.nhs.uk

1 The Institute for Science and Technology in Medicine, Keele University, Stoke-on-Trent, UK

2 Department of Surgery, Royal Stoke University Hospital, Stoke-on-Trent ST4 6RG, UK

3 Health Informatics Department, University Hospitals Birmingham, Birmingham, UK

4 Department of Surgery, Mid Cheshire Hospitals NHS Foundation Trust, Crewe, UK
BDR. Patients who underwent BDR were 10 times more likely to die within a year than those who did not require further surgery (6 vs. $0.6 \%$ ).

Conclusions The rate of BDR following laparoscopic cholecystectomy in England is low $(0.09 \%)$. The study suggests that OTC should be used more widely and provides further evidence in support of the provision of LC services by specialised teams with an adequate caseload $(>80)$.

Keywords Bile duct injury - Bile duct reconstruction . Hospital Episode Statistics data · Laparoscopic cholecystectomy $\cdot$ On-table cholangiography

Laparoscopic cholecystectomy (LC) is a common operation, with over 60,000 operations undertaken each year in England. Based on conversion rate, it has been suggested that LC should be undertaken by high-volume surgeons [1].

Bile duct injury (BDI) is a rare but serious complication of cholecystectomy, and the reported incidence following LC is between 0.1 and $1.5 \%$ [2-8]. Gallrick et al showed that the overall incidence of BDI was $1.5 \%$; however, they included patients with bile leaks, partial duct injury, and non-specific injuries that would not have required reconstruction. The rate decreases to $0.1 \%$ if only the most serious cases of BDI are included [6]. BDI is associated with significant morbidity and mortality. Early complications include collections or peritonitis and if not treated sepsis, multiorgan failure and death [9]. Patients who sustain a BDI are also at risk of long-term problems including strictures, cholangitis and secondary biliary cirrhosis, requiring multiple hospital admissions, a shortened life expectancy and transplantation. The reported perioperative mortality rate following BDI varies between 0 and 
$7.2 \%[5,10-12]$ with a 1-year mortality of $3.9 \%$ [6]. A review of the literature showed (602 BDI from 15 studies) that the adjusted hazard ratio of death in the longer term in those sustaining BDI compared to those without BDI following LC or attempted LC was 2.79 (95 \% CI 2.77-2.81) [4].

This study investigates bile duct reconstruction (BDR) following LC or attempted LC in England as a surrogate marker for major bile duct injury requiring reconstruction.

\section{Methods}

Hospital Episode Statistics (HES) data were obtained from the National Health Service Information Centre (NHSIC) and imported into Microsoft SQL server for analysis. All patients who underwent LC or attempted LC between April 2001 and March 2013 were identified by searching the operative fields for the OPCS-4 (Office of Population Censuses and Surveys 4) codes J18* (cholecystectomy) and the corresponding laparoscopic codes.

Using diagnostic codes, International classification of Diseases version 10 (ICD 10), patients undergoing surgery for benign biliary disease of the gall bladder were identified. Those who underwent LC or attempted LC for a stone in the bile duct or for a malignant neoplasm of the liver, gall bladder, biliary tree or pancreas were excluded.
There is no specific code for BDI in either ICD-10 or OPCS-4; therefore, operative codes that are used for BDR were used to identify patients who required biliary reconstruction following LC or attempted LC. The cohort of patients was followed using HESID (a unique identifier for each patient in HES) to identify patients who underwent BDR within a year of the index operation. If a patient underwent more than one BDR, only the first operation was included in the analysis. A flow chart of the methods is shown in Fig. 1, and all codes used are summarised in Table 1.

Factors that may affect the risk of BDR were divided into patient and non-patient groups. Patient-related factors studied included age, gender, acute pancreatitis, acute cholecystitis, comorbidity and deprivation index score. The Charlson comorbidity score was calculated using methods described by Dr Foster [13]. The deprivation index score was used as described in the English indices of deprivation [14].

Non-patient-related factors included were consultant caseload, hospital volume, consultant conversion rate, whether a trust was a regional hepatopancreatobiliary (HPB) centre and consultant rate of use of intraoperative cholangiography (IOC). Definitions are summarised in Table 2 .

Mortality was assessed for all patients using data derived from the Office of National Statistics. One-year

Fig. 1 Study design

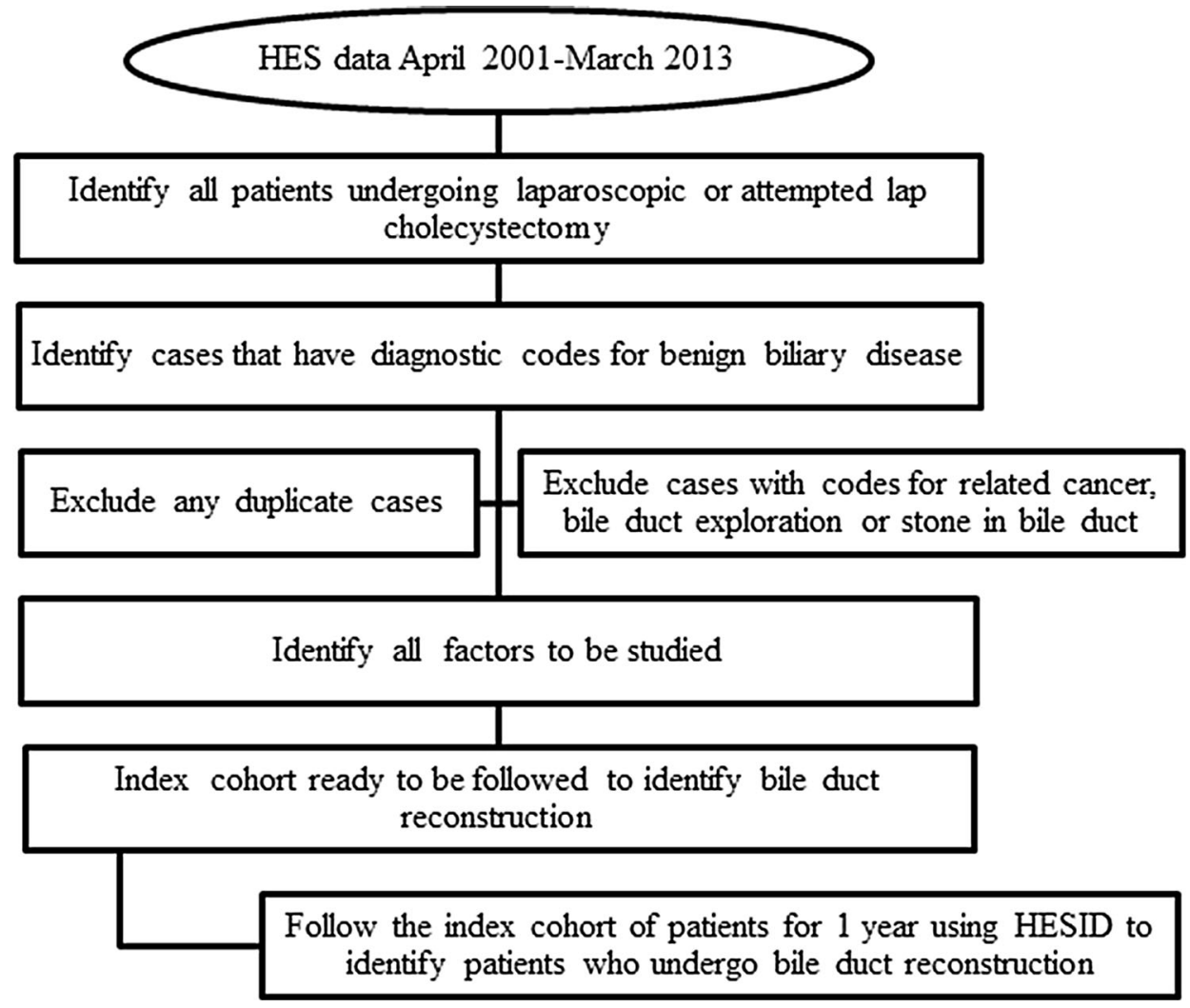


Table 1 Operative and diagnostic codes used in this study

\begin{tabular}{|c|c|}
\hline \multicolumn{2}{|c|}{ Codes used for cholecystectomy } \\
\hline J181 & Total cholecystectomy and surrounding tissue \\
\hline $\mathrm{J} 183$ & Total cholecystectomy \\
\hline $\mathrm{J} 185$ & Partial cholecystectomy \\
\hline J188 & Other excision of gall bladder \\
\hline J189 & Unspecified excision of gall bladder \\
\hline \multicolumn{2}{|c|}{ Codes used for intraoperative cholangiography } \\
\hline $\mathrm{J} 372$ & Operative cholangiography through cystic duct \\
\hline $\mathrm{J} 373$ & Direct puncture operative cholangiography \\
\hline \multicolumn{2}{|c|}{ Codes used for laparoscopic surgery and conversion } \\
\hline Y718 & Failed minimal access approach converted to open (before 2006) \\
\hline Y714 & Failed minimal access approach converted to open (after 2006) \\
\hline Y508 & Laparoscopic approach to abdominal cavity (before 2006) \\
\hline Y75* & $\begin{array}{l}\text { Laparoscopic approach to abdominal cavity (assisted, robotic, } \\
\text { hand-assisted and other approach) (after 2006) }\end{array}$ \\
\hline \multicolumn{2}{|c|}{ Codes used for diagnosis } \\
\hline K800 & Calculus of gall bladder with acute cholecystitis \\
\hline K801 & Calculus of gall bladder with other cholecystitis \\
\hline K802 & Calculus of gall bladder without cholecystitis \\
\hline K808 & Other cholelithiasis \\
\hline K810 & Acute cholecystitis \\
\hline K811 & Chronic cholecystitis \\
\hline K818 & Other cholecystitis \\
\hline K819 & Unspecified cholecystitis \\
\hline $\mathrm{K} 82 *$ & Other diseases of gall bladder \\
\hline K832 & Perforation of bile duct \\
\hline $\mathrm{K} 85^{*}$ & Acute pancreatitis \\
\hline \multicolumn{2}{|c|}{ Codes used for exclusion in the diagnosis fields } \\
\hline K803 & Calculus of bile duct with cholangitis \\
\hline K804 & Calculus of bile duct with cholecystitis \\
\hline K805 & Calculus of bile duct without cholecystitis or cholangitis \\
\hline K830 & Cholangitis \\
\hline K823 & Fistula of gall bladder \\
\hline K831 & Obstruction of bile duct \\
\hline K833 & Fistula of bile duct \\
\hline $\mathrm{C} 22 *$ & Malignant neoplasm of liver and intrahepatic duct \\
\hline $\mathrm{C} 23$ & Malignant neoplasm of gall bladder \\
\hline $\mathrm{C} 24 *$ & Malignant neoplasm of other parts biliary tract \\
\hline $\mathrm{C} 25^{*}$ & Malignant neoplasm of pancreas \\
\hline \multicolumn{2}{|c|}{ Codes used for exclusions in the operative fields } \\
\hline $\mathrm{J} 182$ & Total cholecystectomy and exploration of common bile duct \\
\hline J184 & Partial cholecystectomy and exploration of common bile duct \\
\hline \multicolumn{2}{|c|}{ Codes used to identify bile duct reconstruction } \\
\hline $\mathrm{J} 27.2$ & Partial excision of bile duct and anastomosis of bile duct to duodenum \\
\hline $\mathrm{J} 27.3$ & Partial excision of bile duct and anastomosis of bile duct to jejunum \\
\hline $\mathrm{J} 27.4$ & Partial excision of bile duct and end-to-end anastomosis of bile duct \\
\hline J29.1 & Anastomosis of hepatic duct to transposed jejunum and insertion of tubal prosthesis HFQ \\
\hline $\mathrm{J} 29.2$ & Anastomosis of hepatic duct to jejunum NEC \\
\hline $\mathrm{J} 30.1$ & Anastomosis of common bile duct to duodenum \\
\hline $\mathrm{J} 30.2$ & Anastomosis of common bile duct to transposed jejunum \\
\hline $\mathrm{J} 30.3$ & Anastomosis of common bile duct to jejunum NEC \\
\hline $\mathrm{J} 32.1$ & Reconstruction of bile duct \\
\hline $\mathrm{J} 32.2$ & Reanastomosis of bile duct \\
\hline
\end{tabular}


Table 2 Definitions used in this study

\begin{tabular}{|c|c|}
\hline Factors & Definitions \\
\hline \multicolumn{2}{|l|}{ Non-patients related factors } \\
\hline Consultant caseload & Total number of operations performed under the care of a consultant in the previous year \\
\hline Consultant conversion rate & $\begin{array}{l}\text { Number of laparoscopic cholecystectomies converted divided by the total number of LC and attemptec } \\
\text { LC under the care of that consultant in the previous year }\end{array}$ \\
\hline Hospital volume & Total number of laparoscopic cholecystectomies performed by an NHS Trust in the previous year \\
\hline $\begin{array}{l}\text { Consultant rate of on- } \\
\text { table cholangiography (OTC) }\end{array}$ & $\begin{array}{l}\text { Number of OTC's performed by a consultant divided by the total number of LC attempted under the } \\
\text { care of that consultant in the previous year }\end{array}$ \\
\hline \multicolumn{2}{|l|}{ Patient-related factors } \\
\hline Acute cholecystitis & $\begin{array}{l}\text { Patients admitted as an emergency with diagnostic codes K800 or K810 who undergo cholecystectomy } \\
\text { on that admission }\end{array}$ \\
\hline Acute pancreatitis & $\begin{array}{l}\text { Patients admitted as an emergency with a diagnostic code of } \mathrm{K} 85^{*} \text { who undergo cholecystectomy on } \\
\text { that admission }\end{array}$ \\
\hline Major bile duct injury & $\begin{array}{l}\text { Patient who underwent bile duct reconstruction within a year of index admission, i.e., } \\
\text { hepaticojejunostomy, hepaticoduodenostomy, or resection of injured bile duct and reanastamosis }\end{array}$ \\
\hline
\end{tabular}

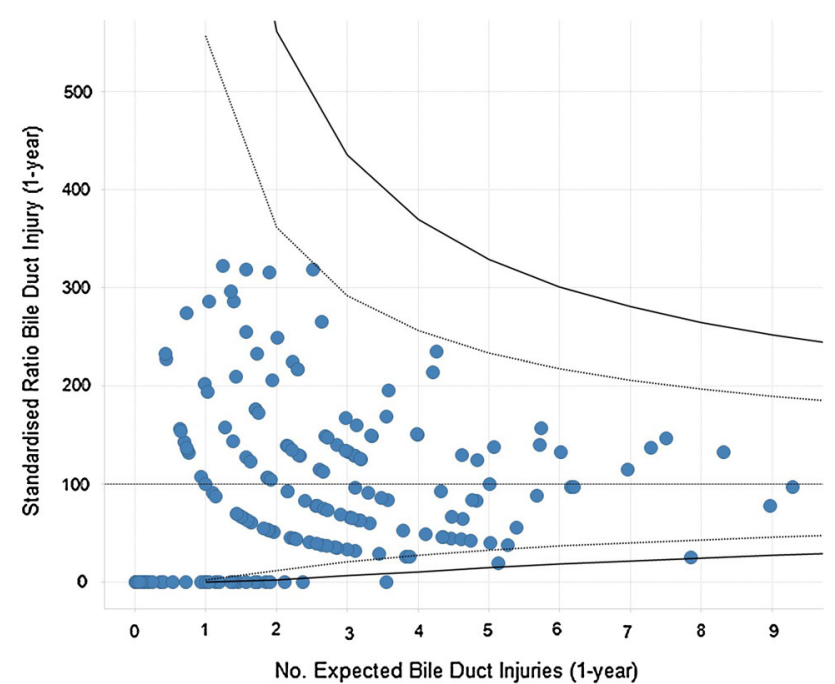

Fig. 2 Funnel plot of Institutional Standardised Ratio for BDR following LC or attempted LC

mortality was then calculated for patients with or without BDR.

\section{Statistics}

Univariate analysis and multivariate analysis (logistic regression) were used to investigate which factors are associated with a risk of bile duct reconstruction.

A funnel plot was used to examine institutional variation and shows the standardised ratio of BDRs at 1 year following LC plotted against the number of expected BDRs (Fig. 2). The expected number of BDRs is derived using a multivariate logistic regression model that accounts for patient-related factors. The BDR ratio was calculated by dividing observed BDR per year over expected BDR per year multiplied by 100 . Each hospital is represented by a blue dot. The dotted lines show the lower and upper $95 \%$ control limit and the solid lines the upper and lower $99.8 \%$ control limit as described by Eayers [15]. If a hospital falls outside the $99.8 \%$ control limit, this is considered to be the result of special cause variation and would usually require further investigation.

\section{Results}

In total, 572,223 LCs and attempted LCs were performed in England between April 2001 and March 2013 (Table 3). More than half $(56 \%)$ were undertaken in patients under 55 years of age, while $7.2 \%$ were performed in patients above 75 years. Just over three quarters of LCs or attempted LCs were undertaken in females. The majority of LCs was performed electively (89\%). Almost a third of emergency LCs were performed for acute cholecystitis and $13.3 \%$ for acute pancreatitis. The number of LCs performed in the NHS in England almost doubled from 32,086 in $2001 / 2002$ to 62,020 during $2012 / 2013$. The overall conversion rate of LC in England is $4.3 \%$. One-year mortality rate following LC in England is $0.6 \%$. Around half of the patients who underwent LC or attempted LC had their surgery under the care of a consultant surgeon who performs between 20 and 80 cases a year, and a quarter of patients underwent surgery under care of consultants who perform less than 20 or more than 80 cases a year.

Five hundred patients underwent BDR within one year of a LC (0.09\%) (Table 3). Patients who underwent BDR following LC were 10 times more likely to die within a year of the index cholecystectomy ( 6 vs $0.6 \%$ ). There is a trend towards a lower rate of BDR (Fig. 3). 
Table 3 Demographics of study cohort

\begin{tabular}{|c|c|c|c|}
\hline & No. of cholecystectomies & Bile duct reconstruction within 1 year & $\%$ \\
\hline Total & 572,233 & 500 & 0.09 \\
\hline \multicolumn{4}{|l|}{ Age group } \\
\hline$<55$ & 319,632 & 220 & 0.07 \\
\hline $55-64$ & 119,663 & 114 & 0.10 \\
\hline $65-74$ & 90,700 & 95 & 0.10 \\
\hline $75+$ & 41,907 & 71 & 0.17 \\
\hline Not recorded & 331 & 0 & 0.00 \\
\hline \multicolumn{4}{|l|}{ Gender } \\
\hline Males & 135,478 & 178 & 0.13 \\
\hline Females & 436,606 & 322 & 0.07 \\
\hline Not recorded & 149 & 0 & 0.00 \\
\hline \multicolumn{4}{|l|}{ Ethnicity } \\
\hline White & 451,869 & 405 & 0.09 \\
\hline Asian or Asian British & 20,106 & 25 & 0.12 \\
\hline Black or Black British & 8,128 & 7 & 0.09 \\
\hline Other ethnic groups & 5,657 & 9 & 0.16 \\
\hline Mixed & 2,315 & 3 & 0.13 \\
\hline Chinese & 1,059 & 0 & 0.00 \\
\hline Unknown & 83,099 & 51 & 0.06 \\
\hline \multicolumn{4}{|l|}{ Deprivation (quintile) } \\
\hline 1-Most deprived & 122,185 & 100 & 0.08 \\
\hline 2 & 118,715 & 114 & 0.10 \\
\hline 3 & 116,686 & 101 & 0.09 \\
\hline 4 & 110,811 & 96 & 0.09 \\
\hline 5-Least deprived & 100,190 & 83 & 0.08 \\
\hline Not recorded & 3,646 & 6 & 0.16 \\
\hline \multicolumn{4}{|l|}{ Tertiary centre } \\
\hline No & 461,346 & 386 & 0.08 \\
\hline Yes & 110,887 & 114 & 0.10 \\
\hline \multicolumn{4}{|l|}{ Admission method } \\
\hline Elective & 510,260 & 435 & 0.09 \\
\hline Emergency & 61,406 & 65 & 0.11 \\
\hline Transfer & 431 & 0 & 0.00 \\
\hline Other & 136 & 0 & 0.00 \\
\hline \multicolumn{4}{|c|}{ Acute cholecystitis (index admission) } \\
\hline No & 551,812 & 478 & 0.09 \\
\hline Yes & 20,421 & 22 & 0.11 \\
\hline \multicolumn{4}{|c|}{ Acute pancreatitis (index admission) } \\
\hline No & 564,077 & 493 & 0.09 \\
\hline Yes & 8,156 & 7 & 0.09 \\
\hline \multicolumn{4}{|l|}{ Year of index admission } \\
\hline $2001 / 2002$ & 32,086 & 28 & 0.09 \\
\hline $2002 / 2003$ & 37,290 & 36 & 0.10 \\
\hline $2003 / 2004$ & 40,824 & 53 & 0.13 \\
\hline $2004 / 2005$ & 39,533 & 33 & 0.08 \\
\hline $2005 / 2006$ & 42,573 & 35 & 0.08 \\
\hline $2006 / 2007$ & 45,049 & 50 & 0.11 \\
\hline $2007 / 2008$ & 50,702 & 43 & 0.08 \\
\hline $2008 / 2009$ & 50,689 & 49 & 0.10 \\
\hline 2009/2010 & 53,748 & 32 & 0.06 \\
\hline
\end{tabular}


Table 3 continued

\begin{tabular}{lccc}
\hline & No. of cholecystectomies & Bile duct reconstruction within 1 year & $\%$ \\
\hline $2010 / 2011$ & 56,254 & 49 & 0.09 \\
$2011 / 2012$ & 61,465 & 52 & 0.08 \\
$2012 / 2013$ & 62,020 & 40 & 0.06 \\
Converted & & \\
Yes & 25,513 & 254 & 1.00 \\
No & 546,720 & 246 & 0.04 \\
No. procedures per institution & (previous year, exc. 2001/2002) & \\
Low volume $<200$ & 113,391 & 82 & 0.07 \\
Middle volume 200-500 & 286,943 & 258 & 0.09 \\
High volume $>500$ & 139,813 & 132 & 0.09 \\
No. procedures per consultant & (previous year, exc. 2001/2002) & \\
Low volume $<20$ & 144,713 & 149 & 0.10 \\
Middle volume 20-80 & 254,224 & 238 & 0.09 \\
High volume $>80$ & 141,210 & 85 & 0.06 \\
\hline
\end{tabular}

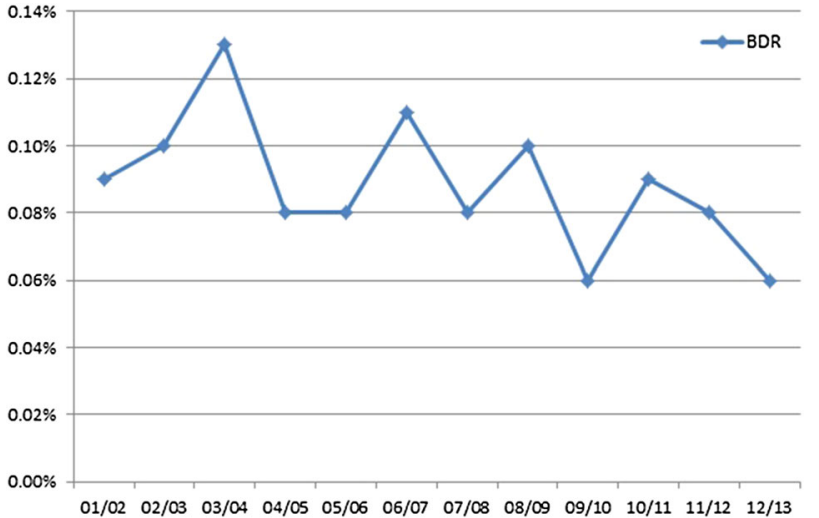

Fig. 3 Bile Duct Reconstruction rate by study year

\section{Patient-related factors}

Univariate analysis showed that patient-related factors including increasing age and male sex were significantly associated with bile duct reconstruction. However, multivariate analysis did not confirm these associations, suggesting that other factors may be responsible for these findings (Table 4). Only patients with acute cholecystitis who undergo LC on the index admission were found by both univariate and multivariate analyses to have an increased risk of BDR.

\section{Non-patient-related factors}

Univariate and multivariate analyses showed that highvolume consultant caseload $>80 \mathrm{LC} / \mathrm{year}$ is associated with a lower rate of BDR.

There was a strong association between conversion and BDR $(p<0.001)$, which may be due to surgeons converting when they suspect a BDI. Therefore, we used consultant conversion rate in the year before rather than conversion in an individual case. There was no association between consultant conversion rate in the previous year and BDR following LC or attempted LC.

Similarly, there was a strong association between the use of OTC and BDR in individual cases $(p<0.001)$. This may be due to surgeons using OTC when they suspect a BDI, but when consultants are divided into tertiles on the basis of their use of OTC in the year before the index case, those who use it more frequently have a lower rate of patients subsequently undergoing bile duct reconstruction, odds ratio 0.69 with $95 \%$ CI (0.54-0.88).

Trust caseload volume was divided into low-volume providers $<200 \mathrm{LC} / \mathrm{year}$, intermediate-volume provider between 200 and 500 LC/year and high-volume providers, which perform more than 500 LC/year. Univariate and multivariate analyses did not show any association between Trust caseload volume and BDR.

There was no difference in the rate of BDR following LC or attempted LC if the index procedure was undertaken in an HPB centre as compared to a non-HPB centre.

A funnel plot was used to examine the rate of BDR following LC/attempted LC in individual trusts. All hospitals were within the $95 \%$ confidence interval. Most BDRs were performed in the hospital in which an injury occurs rather than a regional centre (Table 5).

\section{Discussion}

This is the largest study of its kind in the literature that examines BDR following LC or attempted LC. It investigates all patients who underwent LC in England over a 
Table 4 Multivariate analysis of factors that may be associated with bile duct reconstruction following LC or attempted LC

\begin{tabular}{|c|c|c|c|c|c|c|}
\hline Odds ratio- - bile duct reconstruction & & SE & $z$ & $p$ value & $95 \% \mathrm{CI}$ & \\
\hline Age group $<55$ & 1.00 & & & & & \\
\hline $55-64$ & 0.97 & 0.12 & -0.27 & 0.787 & 0.76 & 1.23 \\
\hline $65-74$ & 0.86 & 0.12 & -1.09 & 0.274 & 0.67 & 1.12 \\
\hline $75+$ & 1.22 & 0.18 & 1.33 & 0.185 & 0.91 & 1.63 \\
\hline Gender females & 0.89 & 0.09 & -1.1 & 0.269 & 0.73 & 1.09 \\
\hline \multicolumn{7}{|l|}{ Deprivation } \\
\hline 1-Most deprived & 1.00 & & & & & \\
\hline 2 & 1.24 & 0.18 & 1.52 & 0.128 & 0.94 & 1.64 \\
\hline 3 & 1.13 & 0.17 & 0.85 & 0.396 & 0.85 & 1.51 \\
\hline 4 & 1.15 & 0.17 & 0.96 & 0.335 & 0.86 & 1.55 \\
\hline 5-Least deprived & 1.11 & 0.17 & 0.65 & 0.513 & 0.81 & 1.51 \\
\hline No acute cholecystitis & 0.48 & 0.11 & -3.12 & 0.002 & 0.30 & 0.76 \\
\hline Acute pancreatitis & 0.81 & 0.34 & -0.5 & 0.620 & 0.36 & 1.83 \\
\hline Charlson score & 0.94 & 0.08 & -0.76 & 0.445 & 0.80 & 1.10 \\
\hline Cholangiography (index admission) & 2.73 & 0.37 & 7.45 & 0.000 & 2.10 & 3.56 \\
\hline Converted procedure & 22.89 & 2.33 & 30.75 & 0.000 & 18.75 & 27.94 \\
\hline \multicolumn{7}{|c|}{ No. procedures per consultant (prev. year, exc. 2001/2002) } \\
\hline Low volume $<20$ & 1.00 & & & & & \\
\hline Middle volume $20-80$ & 0.80 & 0.11 & -1.64 & 0.100 & 0.62 & 1.04 \\
\hline High volume $>80$ & 0.56 & 0.10 & -3.19 & 0.001 & 0.39 & 0.80 \\
\hline \multicolumn{7}{|c|}{ No. procedures per provider (previous year, exc. 2001/2002) } \\
\hline Low volume $<200$ & 1.00 & & & & & \\
\hline Middle volume $200-500$ & 1.07 & 0.18 & 0.37 & 0.710 & 0.76 & 1.49 \\
\hline High volume $>500$ & 1.31 & 0.24 & 1.44 & 0.150 & 0.91 & 1.89 \\
\hline Tertiary hospital & 1.19 & 0.14 & 1.51 & 0.130 & 0.95 & 1.49 \\
\hline \multicolumn{7}{|c|}{ Consultant conversion rate-quartiles (previous year, exc. 2001/2002) } \\
\hline 1-Lowest quartile & 1.00 & & & & & \\
\hline 2 & 1.05 & 0.20 & 0.24 & 0.808 & 0.72 & 1.54 \\
\hline 3 & 1.07 & 0.16 & 0.47 & 0.636 & 0.80 & 1.43 \\
\hline 4-Highest & 0.95 & 0.13 & -0.36 & 0.721 & 0.74 & 1.24 \\
\hline \multicolumn{7}{|c|}{ Consultant cholangiography rate-tertiles (previous year, exc. 2001/2002) } \\
\hline 1-Lowest tertile & 1.00 & & & & & \\
\hline 2 & 1.17 & 0.18 & 1 & 0.318 & 0.86 & 1.58 \\
\hline 3 & 0.69 & 0.09 & -2.98 & 0.003 & 0.54 & 0.88 \\
\hline
\end{tabular}

12-year period. The apparent rate of BDR and therefore presumed bile duct injury is in keeping with published series (the previous literature for major injuries). Patientrelated factors associated with BDR include cholecystitis on the index admission. Non-patient-related factors associated with a lower reconstruction rate include a high consultant cholecystectomy caseload and regular use of OTC. There is a tenfold increase in mortality at 1 year in patients who have undergone a BDR (at 1 year), demonstrating how serious this complication can be.

This study suggests that the incidence of BDR following LC in England is low (0.09\%) with only 500 cases over a 12 -year period. Data from other registries show that the incidence of BDI in Germany is $0.1 \%(172,368$ LC) [2]; in
Denmark $0.15 \%(23,672$ LC) [3]; in the USA between 0.06 and $0.5 \%$ [4, 16]; in Finland $0.82 \%$ (6733 LC) [5]; and in Sweden $1.5 \%(51,041$ LC) [6], although major BDI in this study accounts for only $0.1 \%$. However, researchers have to understand that different definitions of what constitutes BDI make comparative analysis difficult. Other reports from large single-centre studies (over 10,000 LC) showed the incidence of BDI is between $0.19 \%$ [8] and $0.24 \%$ [7]. There was a trend towards a reducing need for BDR during the study period, which may represent an increased awareness of methods of safe cholecystectomy.

The study has a number of limitations. There are no codes for BDI, and we therefore used codes for bile duct reconstruction. Other studies using registry data have used 
Table 5 Bile duct reconstruction at index or another hospital

\begin{tabular}{llll}
\hline $\begin{array}{l}\text { Financial year } \\
\text { (index admission) }\end{array}$ & $\begin{array}{l}\text { No. bile duct } \\
\text { reconstructions }\end{array}$ & $\begin{array}{l}\text { Number performed } \\
\text { at different hospital }\end{array}$ & $\begin{array}{l}\text { \% Bile duct repairs } \\
\text { not in same hospital }\end{array}$ \\
\hline $2001 / 2002$ & 28 & 10 & 35.7 \\
$2002 / 2003$ & 36 & 12 & 33.3 \\
$2003 / 2004$ & 53 & 15 & 28.3 \\
$2004 / 2005$ & 33 & 14 & 42.4 \\
$2005 / 2006$ & 35 & 16 & 45.7 \\
$2006 / 2007$ & 50 & 24 & 48.0 \\
$2007 / 2008$ & 43 & 13 & 30.2 \\
$2008 / 2009$ & 49 & 19 & 38.8 \\
$2009 / 2010$ & 32 & 11 & 34.4 \\
$2010 / 2011$ & 49 & 18 & 36.7 \\
$2011 / 2012$ & 52 & 21 & 40.4 \\
$2012 / 2013$ & 40 & 22 & 55.0 \\
\hline
\end{tabular}

similar methodology $[2-4,17]$. Patients who sustain a BDI and die without surgical intervention will not be included in this analysis. This study only identifies major duct injuries that require reconstruction, whereas minor injuries that require simple repair, drainage or ERCP and stenting are not included. Therefore, the study underestimates the incidence of BDI. Nevertheless, most minor injuries are associated with a lower rate of complications and lower long-term morbidity. However, the study does include those patients who fail to respond to ERCP and stenting or who develop stenosis of bile duct that requires delayed (within a year) surgical reconstruction.

The study uses HES data which are administrative data that rely on the accuracy of clinical coding. A recent systematic review shows that coding accuracy is improving and following the introduction of payment by results in 2002 the accuracy of coding for primary diagnoses has improved from $73.8 \%$ (IQR 59.3-92.1\%) to $96.0 \%$ (IQR 89.3-96.3) [18]. Further studies based on HES are cohort studies; they differ from the usual cohort studies in that they represent almost all activity within the area of study in England. One also has to consider the context of conclusions that are drawn from studies using HES. If findings are of a general nature, then even a relatively high coding error rate at some hospitals or even all hospitals will not detract markedly from the overall conclusions if significant deviation can be shown [19]. Thus, studies based on HES data may actually be good at dealing with research questions such as those posed in this study but are less good at identifying variations in care between individual trusts or clinicians [20]. We have not attempted to analyse the incidence of minor bile duct injuries as the coding issues are complex and we feel that it would be difficult to draw valid conclusions from the data.
Cholecystectomy is considered by many surgeons to be more difficult in male as compared to female patients, and this may lead to a higher complication rates. Our data showed male gender is associated with almost double the rate of BDR $(0.13 \%)$ compared to female patients $(0.07 \%)$. However, this difference becomes statistically insignificant when an adjustment is made for other factors.

Age has been shown to be an independent risk factor for BDI [21] and mortality following BDI [4]. Associated comorbidities, frailty, use of anticoagulants and previous abdominal surgery have been postulated to contribute to the increase in risk in the elderly [21]. Data from this study showed BDR following LC in elderly patients $>75$ years $(0.17 \%)$ was more than that in those below 55 years $(0.07 \%)$. However, multivariate analysis did not reveal any significant difference with age which implies that other factors are more important.

The calibre of the bile duct increases with age which may make simple repair easier in older patients [22, 23]. Whether simple suture repair of the bile duct can be accomplished depends on many other factors, for example, the presence of a clean laceration identified at the same time of surgery together with a wide calibre bile duct.

Several studies [24-26] have shown that bile duct injury repaired at an HPB centre is associated with a better outcome as compared to those repaired in a general hospital. Data from this study showed more than half of the injuries were repaired locally. Centralisation of HPB services has progressed rapidly in the UK with most major resections occurring in HPB centres during the study period. Many of those surgeons who used to perform resectional biliary surgery may still practice in their local hospital. Further some regions offer an outreach service where a BDI injury may be treated in the local hospital by a surgeon from the regional unit. 
Most surgeons in the UK perform OTC selectively. Large studies based on registry data have produced conflicting results. While some show that the risk of BDI decreases when OTC is performed, [6, 17, 27-29] others, including a systematic review [30] show no benefit [31]. The study showed that surgeons who use OTC more frequently have a lower rate of BDR following LC.

The study did not show any difference in BDR following LC between low- and high-volume NHS providers or HPB centres and general hospitals, suggesting that all NHS providers deliver a satisfactory cholecystectomy service. However, it appears consultant caseload is an independent risk factor for BDR following LC. Surgeons who perform $80 \mathrm{LC} /$ year or more have a lower rate of BDR than lowvolume surgeons. Further BDR appears to be more common in patients who undergo cholecystectomy on an index emergency admission with acute cholecystitis.

These results suggest that more widespread use of OTC could also help to reduce the incidence of BDI. They do not support centralisation of cholecystectomy services; however, they do suggest that to avoid major bile duct injury the development of dedicated teams in each hospital with an adequate LC caseload ( $>80)$ may help to reduce the incidence of this complication and further suggests that the occasional operator should reconsider their practice especially in emergency patients.

Author's contribution All authors have made substantial contributions to the conception or design of the work and drafting the work or revising it critically for important intellectual content. All authors approved the final version to be published. An agreement to be accountable for all aspects of the work in ensuring that questions related to the accuracy or integrity of any part of the work are appropriately investigated and resolved.

\section{Compliance with ethical standards}

Disclosures Y. El-Dhuwaib, J. Slavin, D. J. Corless, I. Begaj, D. Durkin and M. Deakin have declare that they have no financial interests (including employment, significant share ownership, patent rights, consultancy, research funding, speaker's fees) in a company or institution that might benefit from the publication of the submitted article.

Open Access This article is distributed under the terms of the Creative Commons Attribution 4.0 International License (http://crea tivecommons.org/licenses/by/4.0/), which permits unrestricted use, distribution, and reproduction in any medium, provided you give appropriate credit to the original author(s) and the source, provide a link to the Creative Commons license, and indicate if changes were made.

\section{References}

1. Ballal M, David G, Willmott S, Corless DJ, Deakin M, Slavin JP (2009) Conversion after laparoscopic cholecystectomy in England. Surg Endosc 23:2338-2344
2. AQUA (2011) German hospital quality report. Institute for Applied Quality Improvement and Research in Health Care GmbH Press, Göttingen

3. Harboe KM, Bardram L (2011) Nationwide quality improvement of cholecystectomy: results from a national database. Int $\mathrm{J}$ Qual Health Care 23:565-573

4. Flum DR, Cheadle A, Prela C, Dellinger EP, Chan L (2003) Bile duct injury during cholecystectomy and survival in medicare beneficiaries. JAMA 290:2168-2173

5. Karvonen J, Salminen P, Gronroos JM (2011) Bile duct injuries during open and laparoscopic cholecystectomy in the laparoscopic era: alarming trends. Surg Endosc 25:2906-2910

6. Tornqvist B, Stromberg C, Persson G, Nilsson M (2012) Effect of intended intraoperative cholangiography and early detection of bile duct injury on survival after cholecystectomy: population based cohort study. BMJ 345:e6457

7. Grbas H, Kunisek L, Zelic M, Petrosic N, Cepic I, Pirjavec A, Lovasic F, Uravic M (2013) Outcome evaluation of 10,317 laparoscopic cholecystectomies: a 17-year experience at a single center. Hepatogastroenterology 60:1873-1876

8. Pekolj J, Alvarez FA, Palavecino M, Sanchez Claria R, Mazza O, de Santibanes E (2013) Intraoperative management and repair of bile duct injuries sustained during 10,123 laparoscopic cholecystectomies in a high-volume referral center. J Am Coll Surg 216:894-901

9. Connor S, Garden OJ (2006) Bile duct injury in the era of laparoscopic cholecystectomy. Br J Surg 93:158-168

10. Nuzzo G, Giuliante F, Giovannini I, Murazio M, D'Acapito F, Ardito F, Vellone M, Gauzolino R, Costamagna G, Di Stasi C (2008) Advantages of multidisciplinary management of bile duct injuries occurring during cholecystectomy. Am J Surg 195:763-769

11. Sicklick JK, Camp MS, Lillemoe KD, Melton GB, Yeo CJ, Campbell KA, Talamini MA, Pitt HA, Coleman J, Sauter PA, Cameron JL (2005) Surgical management of bile duct injuries sustained during laparoscopic cholecystectomy: perioperative results in 200 patients. Ann Surg 241:786-792 (discussion 793-785)

12. de Santibanes E, Palavecino M, Ardiles V, Pekolj J (2006) Bile duct injuries: management of late complications. Surg Endosc 20:1648-1653

13. Paul Aylin AB, Jen Min Hua, Middleton Steven (2011) A toolkit on hospital standardised mortality ratios. Dr Foster Unit at Imperial, Imperial College, London

14. Noble Dm M, Wilkinson K, Whitworth A, Barnes H, Dibben C (2008) The English indices of deprivation 2007. Communities and Local Government Publications, London

15. Eayres D (2008) Commonly used public health statistics and their confidence intervals. APHO, Association of Public Health Observatories, info@apho.org.uk, York

16. Fullum TM, Downing SR, Ortega G, Chang DC, Oyetunji TA, Van Kirk K, Tran DD, Woods I, Cornwell EE, Turner PL (2013) Is laparoscopy a risk factor for bile duct injury during cholecystectomy? JSLS 17:365-370

17. Waage A, Nilsson M (2006) Iatrogenic bile duct injury: a population-based study of 152776 cholecystectomies in the swedish inpatient registry. Arch Surg 141:1207-1213

18. Burns EM, Rigby E, Mamidanna R, Bottle A, Aylin P, Ziprin P, Faiz OD (2012) Systematic review of discharge coding accuracy. J Public Health (Oxf) 34:138-148

19. Hansell A, Bottle A, Shurlock L, Aylin P (2001) Accessing and using hospital activity data. J Public Health Med 23:51-56

20. Slavin JP, Deakin M, Wilson R (2012) Surgical research and activity analysis using Hospital Episode Statistics. Ann R Coll Surg Engl 94:537-538 
21. Aziz H, Pandit V, Joseph B, Jie T, Ong E (2015) Age and obesity are independent predictors of bile duct injuries in patients undergoing laparoscopic cholecystectomy. World J Surg 39:1804-1808

22. Perret RS, Sloop GD, Borne JA (2000) Common bile duct measurements in an elderly population. J Ultrasound Med 19:727-730 (quiz 731)

23. Benjaminov F, Leichtman G, Naftali T, Half EE, Konikoff FM (2013) Effects of age and cholecystectomy on common bile duct diameter as measured by endoscopic ultrasonography. Surg Endosc 27:303-307

24. Schmidt SC, Langrehr JM, Hintze RE, Neuhaus P (2005) Longterm results and risk factors influencing outcome of major bile duct injuries following cholecystectomy. Br J Surg 92:76-82

25. De Santibáñes E, Ardiles V, Pekolj J (2008) Complex bile duct injuries: management. HPB 10:4-12

26. Mercado MA, Franssen B, Dominguez I, Arriola-Cabrera JC, Ramirez-Del Val F, Elnecave-Olaiz A, Aramburo-Garcia R, Garcia A (2011) Transition from a low: to a high-volume centre for bile duct repair: changes in technique and improved outcome. HPB (Oxford) 13:767-773
27. Flum DR, Dellinger E, Cheadle A, Chan L, Koepsell T (2003) INtraoperative cholangiography and risk of common bile duct injury during cholecystectomy. JAMA 289:1639-1644

28. Alvarez FA, de Santibañes M, Palavecino M, Sánchez Clariá R, Mazza O, Arbues G, de Santibañes E, Pekolj J (2014) Impact of routine intraoperative cholangiography during laparoscopic cholecystectomy on bile duct injury. Br J Surg 101:677-684

29. Buddingh KT, Nieuwenhuijs V, van Buuren L, Hulscher JF, de Jong J, van Dam G (2011) Intraoperative assessment of biliary anatomy for prevention of bile duct injury: a review of current and future patient safety interventions. Surg Endosc 25:2449-2461

30. Ford JA, Soop M, Du J, Loveday BPT, Rodgers M (2012) Systematic review of intraoperative cholangiography in cholecystectomy. Br J Surg 99:160-167

31. Sheffield KM, Riall TS, Han Y, Kuo Y, Townsend CM Jr, Goodwin JS (2013) Association between cholecystectomy with vs without intraoperative cholangiography and risk of common duct injury. JAMA 310:812-820 